\title{
Different response of photosynthetic apparatus to high-light stress in sporotrophophyll and nest leaves of Platycerium bifurcatum
}

\author{
J. OLIWA ${ }^{+}$and A. SKOCZOWSKI \\ Pedagogical University of Cracow, Institute of Biology, Podchorą̇ych 2, 31-084 Cracow, Poland
}

\begin{abstract}
Tropical forest deforestation leads to sudden changes in light conditions, which is a problem for the development of epiphytes, such as Platycerium bifurcatum. High light (HL) results in disturbances of the light phase of photosynthesis and changes in leaf pigment composition. The current study determined differences in fast chlorophyll fluorescence transients and changes in radiation reflectance in sporotrophophylls and nest leaves after one and seven days of HL. In addition, a spectral range was identified with the largest change in reflectance induced by HL. Sporotrophophylls exhibited a stronger response of the photosynthetic apparatus to photoinhibition than that of the nest leaves. Moreover, in sporotrophophylls, disorders of electron transport were visible in the whole O-P phase, and in the nest leaves mainly in the O-J phase. Higher accumulation of photoprotective compounds in sporotrophophylls underlined a different reaction to HL.
\end{abstract}

Additional key words: epiphyte; fern; leaf reflectance; OIJP test.

\section{Introduction}

Plants growing in the natural environment are exposed to the simultaneous impact of many abiotic and biotic stress factors, referred to as multistress. It results in the need for developing defense mechanisms at the structural and functional level both on the basis of adaptation inherited from generation to generation, as well as acclimation, which is a direct response to changes in the environment. One of the components of the multistress is high light, often associated with water deficit (Vanhee et al. 2011). Practically, every stress factor has a direct or indirect effect on photosynthesis and can cause damage to photosynthetic apparatus (Lichtenthaler and Burkart 1999).

Light is a key factor in the process of photosynthesis. Paradoxically, often the amount of light reaching plants is higher than the plant needs. In such situations, excess light becomes a stress factor that can damage the photosynthetic apparatus. Therefore, the influence of light stress on the photosynthetic apparatus is extensively studied and has been widely described in many scientific papers (for review see Li et al. 2009). Imbalance between quantity of light energy and low supply of ADP and NADP+ plays an important role and it can lead to disturbances in the functioning of PSII (Force 2003, Weng et al. 2005). Longterm effects of mild to moderate light stress may induce changes in the spatial arrangement of chloroplasts, cause a decrease in chlorophyll (Chl) content or a reduction in the number of active LHCII. Plasticity in the functioning of chloroplasts, i.e., changes in photosystem stoichiometry and increasing plant tolerance to HL (Chernev et at. 2006). However, the rapid increase in the light intensity often induces reduction in the photosynthetic capacity of plants, so-called photoinhibition (Bertamini et al. 2004). For this reason, the plants have developed various photoprotective strategies, which are the subject of many scientific works. They rely, for example, on the detoxication of reactive oxygen species, which arise after absorption of excess light energy, or on the dissipation of excess energy as heat (Logan et al. 2014, Brestic et al. 2015, Foyer 2018, Malnoë 2018). In thermal dissipation of excess energy, protective pigments such as anthocyanins play an important role (Cooney et al. 2018, Demmig-Adams 2018, Gould et al. 2018). In addition, some plants (including ferns, for example Polystichum acrostichoides) limit the absorption of light by changing the leaf angle (Forget et al. 2018). The plant's response to excess light is also dependent on its growth rate (Demmig-Adams et al. 2017). The shade plants may exhibit high susceptibility to photoinhibition.

$\overline{\text { Received }} 4$ June 2018, accepted 12 September 2018.

${ }^{+}$Corresponding author; email: jakub.oliwa@up.krakow.pl

Abbreviations: ABS/RC - apparent antenna size of active PSII RC; Area - surface area; ARI - anthocyanin reflectance index; Chl $a-$ chlorophyll $a$; CRI - carotenoid reflectance index; $\mathrm{DI}_{0} / \mathrm{RC}$ - total energy dissipation not trapped by the PSII $\mathrm{RC} ; \mathrm{ET}_{0} / \mathrm{RC}_{-}$rate of electron transfer by the active PSII RC; $\mathrm{F}_{0}$ - minimum fluorescence; $\mathrm{F}_{\mathrm{K}} / \mathrm{F}_{\mathrm{J}}$ - indicator of inhibition of electron donation by OEC; $\mathrm{FL}$ - fluorescence; FRI - flavonol reflectance index; $\mathrm{F}_{\mathrm{V}} / \mathrm{F}_{0}$ - indicator of structural damage of thylakoids; $\mathrm{F}_{\mathrm{V}} / \mathrm{F}_{\mathrm{M}}-$ maximum quantum yield of PSII; HL - high light; $\mathrm{M}_{0}$ - rate of closure of reaction centers; OEC - oxygen-evolving complex; PI - PSII vitality index; PQ plastoquinone pool; PRI - photochemical reflectance index; $\mathrm{RE}_{0} / \mathrm{RC}$ - quantum yield of electron transport from $\mathrm{Q}_{\mathrm{A}}^{-}$to the PSI end electron acceptors; RC - reaction center; $\mathrm{RD}$ - reflectance difference; SIPI - structure-insensitive pigment index; $\mathrm{S}_{\mathrm{M}}$ - pool size of the electron acceptors $\mathrm{Q}_{\mathrm{A}}$ on the reducing side of PSII; $\mathrm{TR}_{0} / \mathrm{RC}$ - energy trapping of one active reaction center; WBI - water band index; $\varphi_{E 0}-$ quantum yield for electron transport from $\mathrm{Q}_{\mathrm{A}}{ }^{-}$to plastoquinone. 
However, in this case, the inactivated PSII cores can act as photoprotectors (Malnoë 2018) and provide protection of the photosynthetic apparatus from damage (Bertamini et al. 2004, Demmig-Adams 2018).

The sudden change in light conditions is an increasingly serious problem for valuable species of epiphytic ferns growing in tropical forests like Platycerium bifurcatum (Barthlott et al. 2001, Adibah and Ainuddin 2011). Changes in light conditions in forests may result from natural causes (death of trees) or from anthropogenic pressure (cutting out large fragments of forest). In the latter case, the intensity of light increases on a large area adjacent to the fragment cut. In addition, anthropogenic pressure in tropical forests contributes to the imbalance of the environment and irreversible destruction of the microclimate, which may result in the loss of species diversity.

Currently, it is believed that drought stress is the most important among the factors limiting the development of epiphytes; other factors (including photoinhibition) are of minor importance (Zotz and Hietz 2001). However, according to current knowledge, such an approach does not allow a proper understanding physiology and ecology of epiphytes, hence there is a need to conduct research on the physiological response of these plants to abiotic stresses. In spite of the ecophysiological research, still little is known about the physiological mechanisms that allow epiphytes to cope with light excess. So far it has been demonstrated that biochemical mechanisms based on energy dissipation via xanthophyll, similar to those in spermatophytes, are also present in ferns (Eickmeier et al. 1993, Tausz et al. 2001).

The previous research on $P$. bifurcatum physiology was primarily associated with ensuring proper growing conditions and micropropagation methods of these ornamental plants (Aspiras et al. 2010, Liao and Wu 2011). In addition, drought stress response was investigated by Rut et al. (2003), and the subject of intense light stress was studied by Sanusi et al. (2011). However, there is still a lack of information on the response of the photosynthetic apparatus to the sudden increase in light intensity, e.g., after tree logging in a large forest area. The hitherto rating of light-shock reaction does not fully correspond to the changes of the light intensity in the natural environment (often PPFD $<1,500 \mu \mathrm{mol} \mathrm{m} \mathrm{m}^{-2} \mathrm{~s}^{-1}$ ). The continuous intensification of human activities in tropical climate forests is therefore an important reason for more extended research.

Platycerium bifurcatum sporophyte, as some other species of epiphytic ferns, is characterized by heterophylly (Fig. 1). Long, ribbon-like sporotrophophylls have an assimilatory role, while nest leaves, which support the plant, show different physiological features and even a different type of metabolism $\left(\mathrm{C}_{3}\right.$ in sporotrophophylls, CAM in nest leaves - Rut et al. 2008, Oliwa et al. 2017). Heterophylly is very rarely considered in ecophysiological studies. However, for an assessment of physiological state of the whole plant, conditions of nest leaves should be taken into account, due to possible translocation of metabolites from nest leaves to sporotrophophylls during their terminal stage (Oliwa et al. 2017).

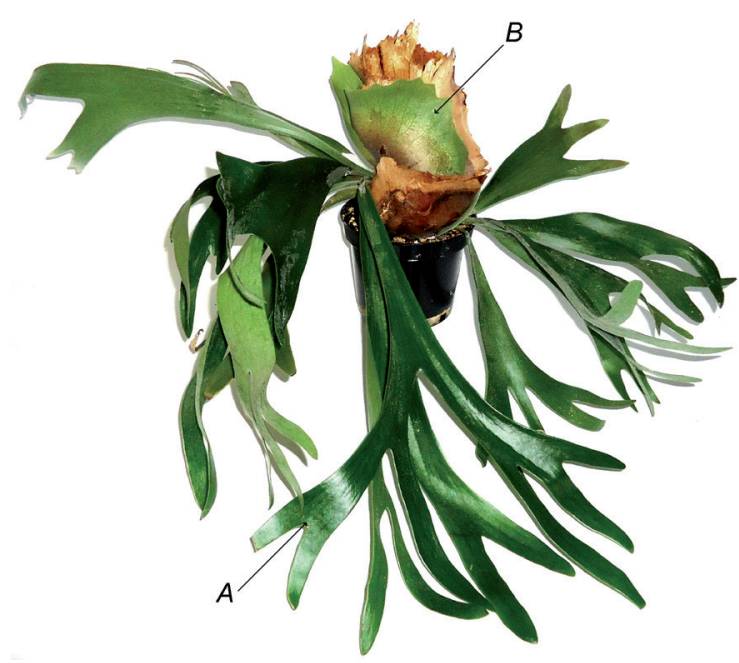

Fig. 1. Epiphytic fern Platycerium bifurcatum. The figure shows two types of leaves: sporotrophophylls $(A)$ and nest leaves $(B)$.

The use of nondestructive research methods based on Chl $a$ fluorescence (FL) allowed in this study to determine changes at the physiological level occurring in the same leaves after different HL exposure times. Description of the bioenergetic state of the plant using the analysis of Chl $a$ fluorescence induction curve (OJIP test) reflects electron transport through subsequence elements of the oxidation-reduction chain and communication between individual PSII units (Kalaji and Guo 2008). The OJIP test and Chl $a$ FL parameters are often used for rapid analysis of plant viability and PSII performance estimation under environmental stress conditions (Oukarroum et al. 2007, Mehta et al. 2010, Kalaji et al. 2012, Gururani et al. 2015). In turn, reflectance analysis allows to determine changes in leaf chemical composition (including pigment system restructuring) and the degree of light energy utilization (Solovchenko 2010). It also allows to identify the radiation range, in which PAR reflectance spectrum from leaves changes most dramatically in response to light stress (Carter 1993).

HL stress very quickly induces disturbances in the light phase of photosynthesis. Therefore, the aim of this study was to determine differences in the course of the light phase in sporotrophophyll and nest leaves of $P$. bifurcatum after 1 and $7 \mathrm{~d}$ from the sudden increase in light intensity. In addition, we investigated whether the HL stress response is accompanied by changes in leaf pigment composition and tissue hydration. An attempt was also made to identify the radiation range, in which the greatest change in reflectance caused by HL occurred $\left(\mathrm{PPFD} \leq 800 \mu \mathrm{mol} \mathrm{m}^{-2} \mathrm{~s}^{-1}\right.$ ).

\section{Materials and methods}

Plant material and growth conditions: Sporophytes of Platycerium bifurcatum grew for six months in an Angelantoni EKOCH 700 (Massa Martana, Italy) growth chamber. The PPFD was $150 \pm 20 \mu \mathrm{mol} \mathrm{m}^{-2} \mathrm{~s}^{-1}$, photoperiod $16 / 8$-h (day/night), temperature $25 / 15^{\circ} \mathrm{C}$ (day/night), relative humidity of $60 \%$. The analyses were carried out on 
sporotrophophyll and nest leaves at their second stage of development (according to the classification of Oliwa et al. 2017). In order to elicit an intense light response, the plants were placed for $7 \mathrm{~d}$ under sodium lamps (Philips $S O N-T$ AGRO $400 \mathrm{~W}$, The Netherlands), and PPFD was increased to a value of $\leq 800 \mu \mathrm{mol} \mathrm{m} \mathrm{m}^{-2} \mathrm{~s}^{-1}$.

Chl $\boldsymbol{a}$ fluorescence kinetics: Parameters of PSII photochemical efficiency were measured according to the method described by Strasser et al. (2000) using a HandyPEA fluorometer (Hansatech Instruments, King's Lynn, UK). The part of intact leaf blade was acclimated to darkness for 20 min using a clip equipped with an iris. Chl $a$ fluorescence was induced by PPFD of $3 \mathrm{mmol} \mathrm{m}^{-2} \mathrm{~s}^{-1}$. The following fluorescence intensity measurement points were adopted for the OJIP test: $\mathrm{O}-20 \mu \mathrm{s}, \mathrm{J}-2 \mathrm{~ms}$, I $30 \mathrm{~ms}, \mathrm{P}-300 \mathrm{~ms}$. The differential curves of Chl $a$ FL kinetics $(\Delta \mathrm{Vt})$ were calculated by subtracting the normalized (to $\mathrm{O}$ and $\mathrm{P}$ points) FL values in plants growing for 1 or $7 \mathrm{~d}$ under HL from the normalized values obtained for control. This way of counting makes the differences between treatments more visible. The measurement results were compiled in the PEA Plus program (Hansatech, UK) and MS Excel 2010 and selected parameters of the Chl $a$ fluorescence kinetics were analyzed: $\mathrm{F}_{\mathrm{V}} / \mathrm{F}_{\mathrm{M}}, \mathrm{F}_{\mathrm{V}} / \mathrm{F}_{0}$, Area, PI, $\mathrm{S}_{\mathrm{M}}, \mathrm{M}_{0}, \varphi_{\mathrm{E} 0}$ (Strasser et al. 2004, Stirbet and Govindjee 2011), $\mathrm{F}_{\mathrm{K}} / \mathrm{F}_{\mathrm{J}}$ (Srivastava and Strasser 1995) and the following energy flux parameters by $\mathrm{RC}: \mathrm{TR}_{0} / \mathrm{RC}$, $\mathrm{ET}_{0} / \mathrm{RC}, \mathrm{RE}_{0} / \mathrm{RC}, \mathrm{DI}_{0} / \mathrm{RC}, \mathrm{ABS} / \mathrm{RC}$ (Strasser et al. 2004, Stirbet and Govindjee 2011). The calculation equations of the used parameters are shown in the following table:

Summary of measured and calculated Chl a fluorescence parameters, References: (1) Strasser et al. 2004, (2) Yusuf et al. 2010, (3) Stirbet and Govindjee 2011.

\begin{tabular}{lll}
\hline Parameter & Formula & Reference \\
\hline $\mathrm{F}_{0}$ & $\mathrm{~F}_{0.05 \mathrm{~ms}}$ & $(1)$ \\
$\mathrm{F}_{\mathrm{K}}$ & $\mathrm{F}_{0.3 \mathrm{~ms}}$ & $(2)$ \\
$\mathrm{F}_{\mathrm{J}}$ & $\mathrm{F}_{2 \mathrm{~ms}}$ & $(1)$ \\
$\mathrm{F}_{\mathrm{I}}$ & $\mathrm{F}_{30 \mathrm{~ms}}$ & $(1)$ \\
$\mathrm{F}_{\mathrm{M}}$ & $\mathrm{F}_{300 \mathrm{~ms}}$ & $(1)$ \\
$\mathrm{F}_{\mathrm{V}}$ & $\mathrm{F}_{\mathrm{V}}=\mathrm{F}_{\mathrm{M}}-\mathrm{F}_{0}$ & $(1)$ \\
$\mathrm{M}_{0}$ & $\mathrm{M}_{0}=4\left(\mathrm{~F}_{\mathrm{K}}-\mathrm{F}_{0}\right) /\left(\mathrm{F}_{\mathrm{M}}-\mathrm{F}_{0}\right)$ & $(1)$ \\
$\mathrm{S}_{\mathrm{M}}$ & $\mathrm{S}_{\mathrm{M}}=\mathrm{Area} /\left(\mathrm{F}_{\mathrm{M}}-\mathrm{F}_{0}\right)$ & $(1)$ \\
$\mathrm{V}_{\mathrm{J}}$ & $\mathrm{V}_{\mathrm{J}}=\left(\mathrm{F}_{\mathrm{J}}-\mathrm{F}_{0}\right) /\left(\mathrm{F}_{\mathrm{M}}-\mathrm{F}_{0}\right)$ & $(1)$ \\
$\mathrm{V}_{\mathrm{I}}$ & $\mathrm{V}_{\mathrm{I}}=\left(\mathrm{F}_{\mathrm{I}}-\mathrm{F}_{0}\right) /\left(\mathrm{F}_{\mathrm{M}}-\mathrm{F}_{0}\right)$ & $(1)$ \\
$\varphi \mathrm{E}_{0}$ & $\varphi \mathrm{E}_{0}=\left[1-\left(\mathrm{F}_{0} / \mathrm{F}_{\mathrm{M}}\right)\right]\left(1-\mathrm{V}_{\mathrm{J}}\right)$ & $(1)$ \\
$\psi \mathrm{E}_{0}$ & $\psi \mathrm{E}_{0}=\left(1-\mathrm{V}_{\mathrm{J}}\right)$ & $(1)$ \\
$\mathrm{ABS} / \mathrm{RC}$ & $\mathrm{ABS}_{\mathrm{B}} / \mathrm{RC}=\mathrm{M}_{0}\left(1 / \mathrm{V}_{\mathrm{J}}\right)\left[1-\left(\mathrm{F}_{0} / \mathrm{F}_{\mathrm{M}}\right)\right]$ & $(1)$ \\
$\mathrm{TR}_{0} / \mathrm{RC}$ & $\mathrm{TR}_{0} / \mathrm{RC}=\mathrm{M}_{0}\left(1 / \mathrm{V}_{\mathrm{J}}\right)$ & $(1)$ \\
$\mathrm{ET}_{0} / \mathrm{RC}$ & $\mathrm{ET}_{0} / \mathrm{RC}=\mathrm{M}_{0}\left(1 / \mathrm{V}_{\mathrm{J}}\right) \psi \mathrm{E}_{0}$ & $(1)$ \\
$\mathrm{RE}_{0} / \mathrm{RC}$ & $\mathrm{RE}_{0} / \mathrm{RC}=\left(\mathrm{M}_{0} / \mathrm{V}_{\mathrm{J}}\right)\left(1-\mathrm{V}_{\mathrm{I}}\right)$ & $(3)$ \\
$\mathrm{DI}_{0} / \mathrm{RC}$ & $\mathrm{DI}_{0} / \mathrm{RC}=(\mathrm{ABS} / \mathrm{RC})-\left(\mathrm{TR}_{0} / \mathrm{RC}\right)$ & $(1)$ \\
\hline
\end{tabular}

Radiation reflectance from leaves: Leaf reflectance was measured using a CID Bio-Science CI-710 spectrometer
(CID Bio-Science, Camas, USA) on the upper surface of the leaf. Reflectance spectra in the 400-1,000 nm range were recorded using SpectraSnap software. Then the values of content indices of anthocyanins $\left[\mathrm{ARI}_{1}=\right.$ $\left(\mathrm{R}_{550}{ }^{-1}-\mathrm{R}_{700}{ }^{-1}\right) \mathrm{R}_{800}$, Gitelson et al. 2001], carotenoids (Car) $\left[C \mathrm{CI}_{1}=\left(\mathrm{R}_{520^{-1}}-\mathrm{R}_{550^{-1}}\right) \mathrm{R}_{800}\right.$, Gitelson et al. 2002), flavonoids [FRI $=\left(\mathrm{R}_{410^{-1}}-\mathrm{R}_{460}{ }^{-1}\right) \mathrm{R}_{800}$, Merzlyak et al. 2005 ] were calculated. In addition, the Car to Chl $a$ ratio [SIPI = $\left(\mathrm{R}_{800}-\mathrm{R}_{445}\right)\left(\mathrm{R}_{800}+\mathrm{R}_{680}\right)^{-1}$, Peñuelas et al. 1995] and tissue hydration index [WBI $=\mathrm{R}_{900}\left(\mathrm{R}_{970}\right)^{-1}$, Peñuelas et al. 1993] were determined.

In addition to the above parameters, photochemical reflectance index (PRI), constituting an alternative form of assessing photosynthesis quantum yield and PSII functional efficiency, was also determined [PRI $=\left(\mathrm{R}_{531}-\mathrm{R}_{570}\right)$ $\left(\mathrm{R}_{531}+\mathrm{R}_{570}\right)^{-1}$, Gamon et al. 1992]; it was analyzed separately based on changes in relative values. In the equations, $R_{x}$ means reflectance intensity at a specific $x$ wavelength.

A reflectance difference curve and a curve allowing identification of the wavelength, at which the numerical reflectance value changes the most due to stress action (sensitivity analysis) were determined according to the method of Carter (1993). Reflectance difference (RD) was calculated according to the formula: $R D=R_{S P}-R_{C P}$, where: $\mathrm{R}_{\mathrm{SP}}$ - reflectance intensity (\%) in the range of 400 $1,000 \mathrm{~nm}$ in plants subjected to intense light stress, $\mathrm{R}_{\mathrm{CP}}-$ reflectance intensity (\%) in the range of $400-1,000 \mathrm{~nm}$ in control plants.

Stress-sensitive wavelengths (sensitivity) was calculated by dividing the $\mathrm{RD}$ values by the control values, according to the formula: Sensitivity $=\mathrm{RD}\left(\mathrm{R}_{\mathrm{CP}}\right)^{-1}$

Statistical analysis: The results obtained from seven independent replicates for each of the experimental groups were analyzed by the Statistica 10.0 program (Statsoft, Kraków, Poland) using the analysis of variance (ANOVA) test. The significance of differences between means was estimated using Duncan's test at a significance level of $p \leq 0.05$.

\section{Results}

Analysis of OJIP curves: A strong stress reaction of the photosynthetic apparatus was observed in sporotrophophylls on the first day of growth under HL. There was a significant increase in FL in the $\mathrm{O}-\mathrm{J}$ phase of the Chl $a$ FL induction curve, a decrease in the FL value in the I-P phase, and a complete lack of I step compared with control (Fig. $2 A$ - black and blue lines, respectively). A further increase in FL intensity on the O-I phase was observed after $7 \mathrm{~d}$ under HL. There was an increase in the FL in the J step compared with control, indicating a marked reduction in the efficiency of electron transport. At the same time, the deviation from control on the I-P phase was reduced (Fig. $2 A-$ red line). Nest leaves showed a significantly weaker response to HL stress than that of sporotrophophylls (Fig. 3A). The direction of changes was similar, however, alterations in FL intensity in all phases were much smaller than that in sporotrophophylls, and the shape of the OJIP curve did not differ significantly from 

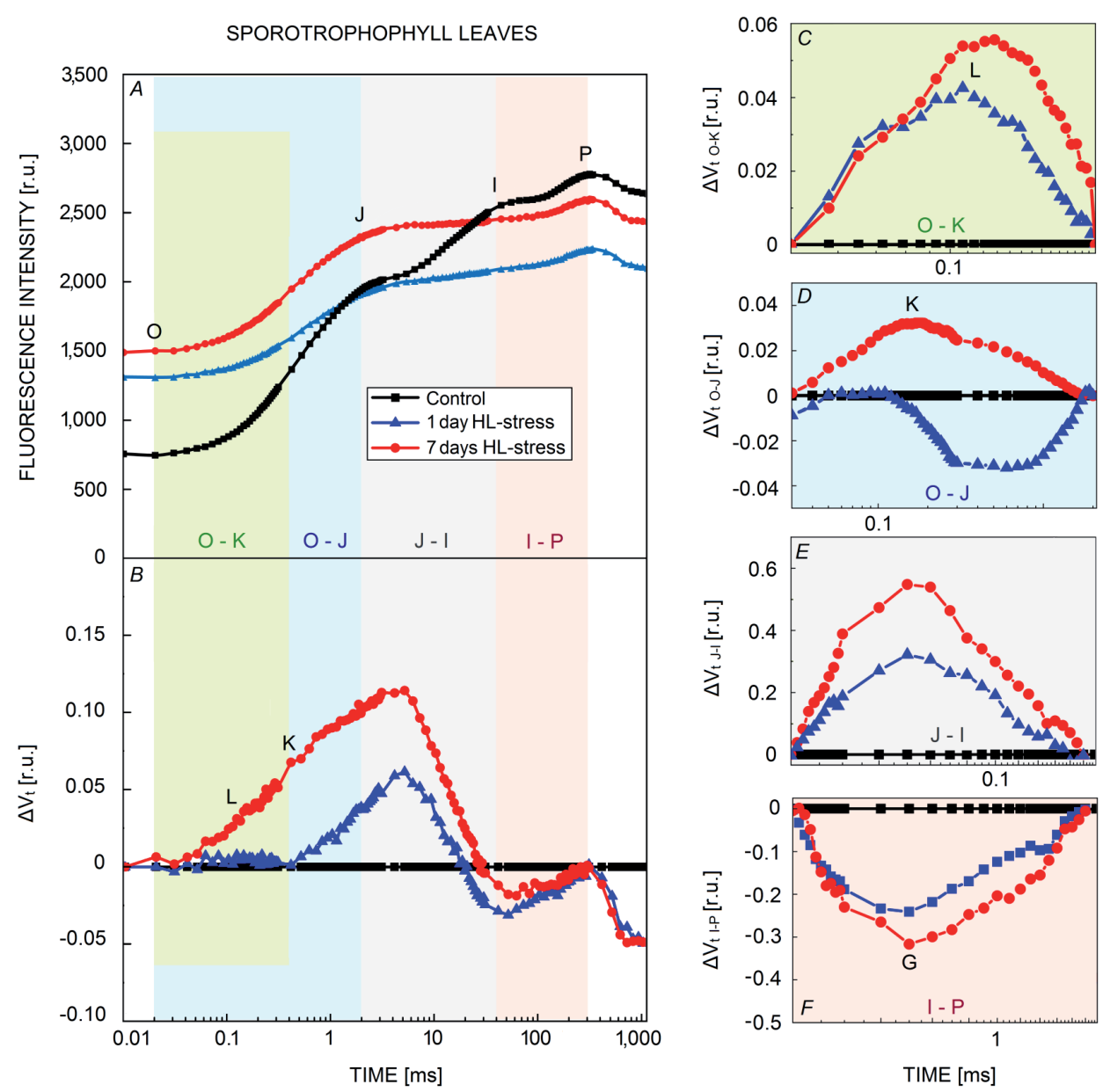

Fig. 2. Induction transients of chlorophyll $a$ fluorescence (OJIP) in the sporotrophophylls of Platycerium bifurcatum after 1- and 7-d growth under high light and in control conditions $(A)$. Differential curves $\Delta \mathrm{V}_{\mathrm{t}}$ for the ranges of $\mathrm{O}-\mathrm{P}(B), \mathrm{O}-\mathrm{K}(C), \mathrm{O}-\mathrm{J}(D), \mathrm{J}-\mathrm{I}(E), \mathrm{I}-\mathrm{P}$ $(F)$ were obtained by subtracting normalized values of chlorophyll fluorescence intensity of stressed plants from control (see Materials and methods), $n=7$.

the control. Noteworthy is the lack of significant changes between the $1^{\text {st }}$ and $7^{\text {th }}$ day of growth under HL. It should also be noted that particular steps on OJIP control curves in nest leaves were less marked than in sporotrophophylls (Figs. 2A, 3A).

The differential curves of Chl $a$ FL kinetic increase changes $(\Delta \mathrm{Vt})$ in sporotrophophylls indicated that significant control deviations occurred over the entire O-P phase (Fig. 2B). However, these differences were significantly lower after one day at HL (especially in the O-I phase) than that after $7 \mathrm{~d}$. Disturbances of the initial stages of the light phase in sporotrophophylls were observed only after a week under HL, which was manifested by an increase in $\mathrm{FL}$ at the $\mathrm{O}-\mathrm{K}$ phase. The main effects of light stress in the nest leaves occurred during the $\mathrm{O}_{-} \mathrm{J}$ and $\mathrm{J}-\mathrm{I}$ phases, and the differences between the $1^{\text {st }}$ and $7^{\text {th }}$ day of growth under HL were visible between $\mathrm{K}-\mathrm{I}$ points (Fig. $3 B$ ).

The differential curves for the $\mathrm{O}-\mathrm{K}, \mathrm{O}-\mathrm{J}, \mathrm{J}-\mathrm{I}$, and I-P phases were calculated analogously to $\Delta \mathrm{Vt}$ (Figs. $2 D-F, 3 D-F)$. The $\mathrm{L}$ and $\mathrm{K}$ bands, characteristic of stress reaction, were evident in both types of leaves treated with $\mathrm{HL}$ on $\mathrm{O}-\mathrm{K}$ and $\mathrm{O}-\mathrm{J}$ differential curves, respectively. The $\mathrm{L}$ band values in sporotrophophylls were significantly higher after $7 \mathrm{~d}$ than after one day at HL (Fig. 2C). There was no such relationship in the nest leaves (Fig. 3C). However, FL intensity in these leaves was higher than that in sporotrophophylls after the first day at HL (Figs. 2C, $3 C$ ). The $\mathrm{K}$ band is clearly marked only in the nest leaves (Fig. 3D). The K band in sporotrophophylls occurred only after $7 \mathrm{~d}$ at HL (Fig. 2D) and had significantly lower values than that in the nest leaves.

Changes in the course of the $\mathrm{J}-\mathrm{I}$ phase, compared with the control, were visible especially after a longer HL action. The $\mathrm{G}$ band, similarly a characteristic of a strong stress (I-P phase), had higher negative values after $7 \mathrm{~d}$ under HL (Fig. 2F). In contrast, the nest leaves growing under stress conditions did not show any significant FL increase at the $\mathrm{J}-\mathrm{I}$ phase in relation to control (Fig. 3E). There were also no typical $\mathrm{G}$ bands, both after 1 and $7 \mathrm{~d}$ of HL (Fig. 3F).

Chl $\boldsymbol{a}$ FL parameters: Changes in PSII photochemical efficiency parameters $\left(\mathrm{F}_{\mathrm{M}}, \mathrm{F}_{\mathrm{V}} / \mathrm{F}_{\mathrm{M}}, \mathrm{F}_{\mathrm{V}} / \mathrm{F}_{0}\right.$, Area, PI, $\mathrm{S}_{\mathrm{M}}$, $\mathrm{M}_{0}, \mathrm{~F}_{\mathrm{K}} / \mathrm{F}_{\mathrm{J}}$ ) in plants growing under $\mathrm{HL}$ are shown in Fig. 4 as a percentage deviation from the control values. Disturbances in the functioning of the photosynthetic 

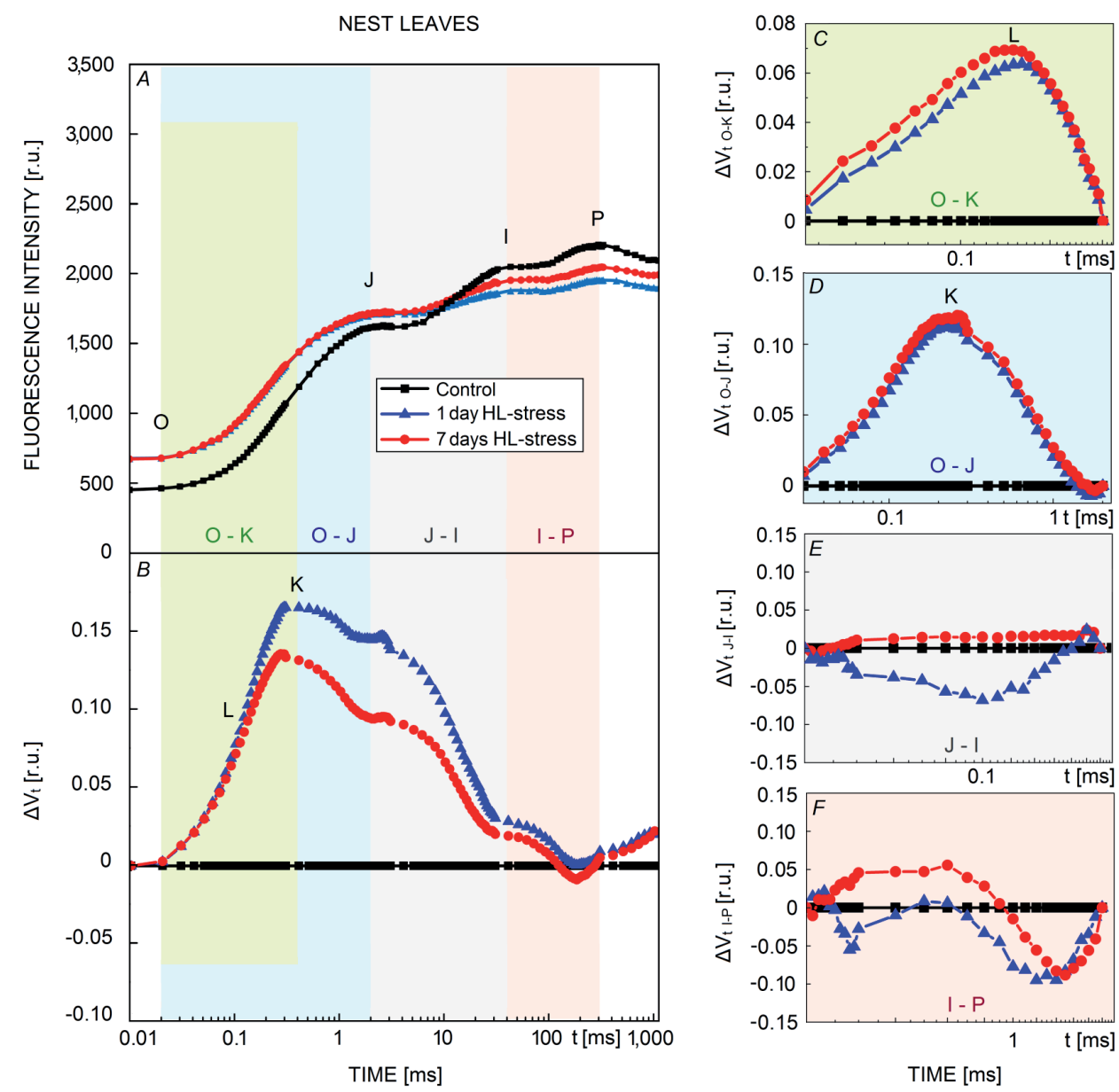

Fig. 3. Induction transients of chlorophyll $a$ fluorescence (OJIP) in the nest leaves of Platycerium bifurcatum after 1- and 7-d growth under high light and in control conditions $(A)$. Differential curves $\Delta \mathrm{V}_{\mathrm{t}}$ for the ranges of $\mathrm{O}-\mathrm{P}(B), \mathrm{O}-\mathrm{K}(C), \mathrm{O}-\mathrm{J}(D), \mathrm{J}-\mathrm{I}(E), \mathrm{I}-\mathrm{P}(F)$ were obtained by subtracting normalized values of chlorophyll fluorescence intensity of stressed plants from control (see Materials and methods), $n=7$.

apparatus of sporotrophophylls occurred after the first day of light stress. After this time, a significant decrease in the value $\mathrm{F}_{\mathrm{V}} / \mathrm{F}_{0}$ and Area by at least $50 \%$, and increase in the values of parameters $\mathrm{F}_{\mathrm{K}} / \mathrm{F}_{\mathrm{J}}$ and $\mathrm{M}_{0}$ was observed (Fig. $4 A$ ). The highest, almost ten-fold decrease was recorded for PI. After 7-d HL, compared to the first day, an increase in the $\mathrm{F}_{\mathrm{M}}$, Area, and $\mathrm{M}_{0}$ parameters was observed.

A decrease in $\mathrm{F}_{\mathrm{V}} / \mathrm{F}_{\mathrm{M}}, \mathrm{F}_{\mathrm{V}} / \mathrm{F}_{0}$, PI, Area, and $\varphi_{\mathrm{E} 0}$ was lower in the nest leaves compared to sporotrophophylls. Differences between the $1^{\text {st }}$ and $7^{\text {th }}$ day of stress were visible in the PI, Area, $\mathrm{F}_{\mathrm{V}} / \mathrm{F}_{0}, \mathrm{~S}_{\mathrm{M}}$, and $\varphi_{\mathrm{E} 0}$ parameters (Fig. $4 B$ ). For the other parameters, no differences were observed between day 1 and 7 of growth under HL. Changes in specific flux parameters in one active reaction center are illustrated in Table 1. An increase in the energy capture and flow through reaction center $(\mathrm{RC})\left(\mathrm{TR}_{0} / \mathrm{RC}, \mathrm{ET}_{0} / \mathrm{RC}\right)$ was recorded after the first day of stress in response to HL in sporotrophophylls. A decrease in $\mathrm{RE}_{0} / \mathrm{RC}$ occurred only after $7 \mathrm{~d}$. In the nest leaves, the changes in $\mathrm{TR}_{0} / \mathrm{RC}$ and $\mathrm{ET}_{0} \mathrm{RC}$ had a similar trend to that of sporotrophophylls, however, between $1^{\text {st }}$ and $7^{\text {th }}$ day of stress, there was no change in $\mathrm{ET}_{0} / \mathrm{RC}$. The size of the active RC PSII antenna did not change (ABS/RC) under HL conditions. The nest leaves (both in control and stressed plants) showed greater dissipation of energy than that of sporotrophophylls $\left(\mathrm{DI}_{0} / \mathrm{RC}\right)$.

Reflectance analysis: In sporotrophophylls, after $7 \mathrm{~d}$ of HL stress, the reflectance intensity only slightly increased in the green spectrum (with a peak around $550 \mathrm{~nm}$ ) whereas in the 700-1,000 nm range was significantly higher as compared with control (Fig. 5A). In nest leaves, an increase in the reflectance intensity was observed in the range of 550-650 nm, while in the far-red part of the spectrum, reflectance decreased under stress conditions (Fig. 5B).

The largest differences in response to stress compared to the control occurred in sporotrophophylls at $535 \mathrm{~nm}$ (Fig. 5C). The reflectance difference (RD) curve of the nest leaves was characterized by a completely different shape (Fig. 5D). The minimum difference in RD occurred in the green range at $550 \mathrm{~nm}$, and was the highest at 650 and 690 nm (Fig. 5D). RD in the far-red and near-infrared range had positive values in sporotrophophylls, while negative values in the nest leaves (Fig. 5C,D).

Sensitivity values in sporotrophophylls were the 
A

SPOROTROPHOPHYLL LEAVES

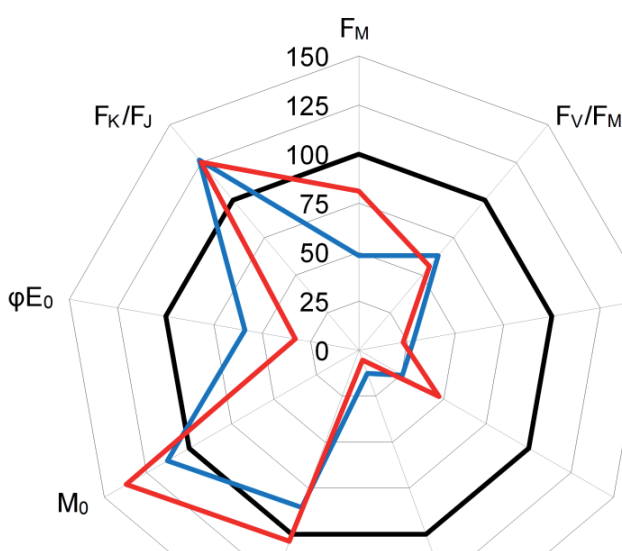

$\mathrm{S}_{\mathrm{M}}$

PI

\section{FFn}

$F_{v} / F_{0}$

Area
B

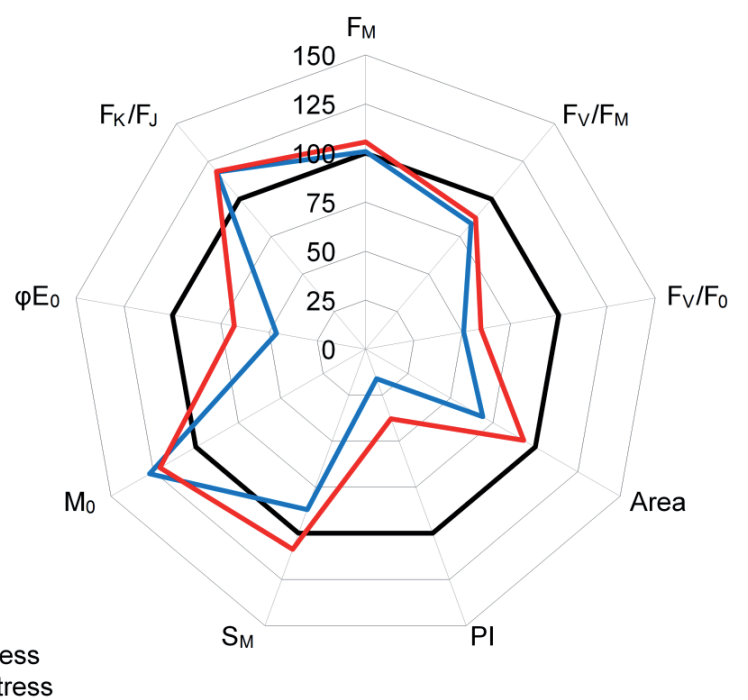

Fig. 4. Values of chlorophyll $a$ fluorescence parameters of the sporotrophophyll $(A)$ and nest leaves $(B)$ of Platycerium bifurcatum after 1- and 7-d growth in high light ( $P P F D=800 \mu \mathrm{mol} \mathrm{m}^{-2} \mathrm{~s}^{-1}$ ). The values are presented as the percentage of the control, $n=7$.

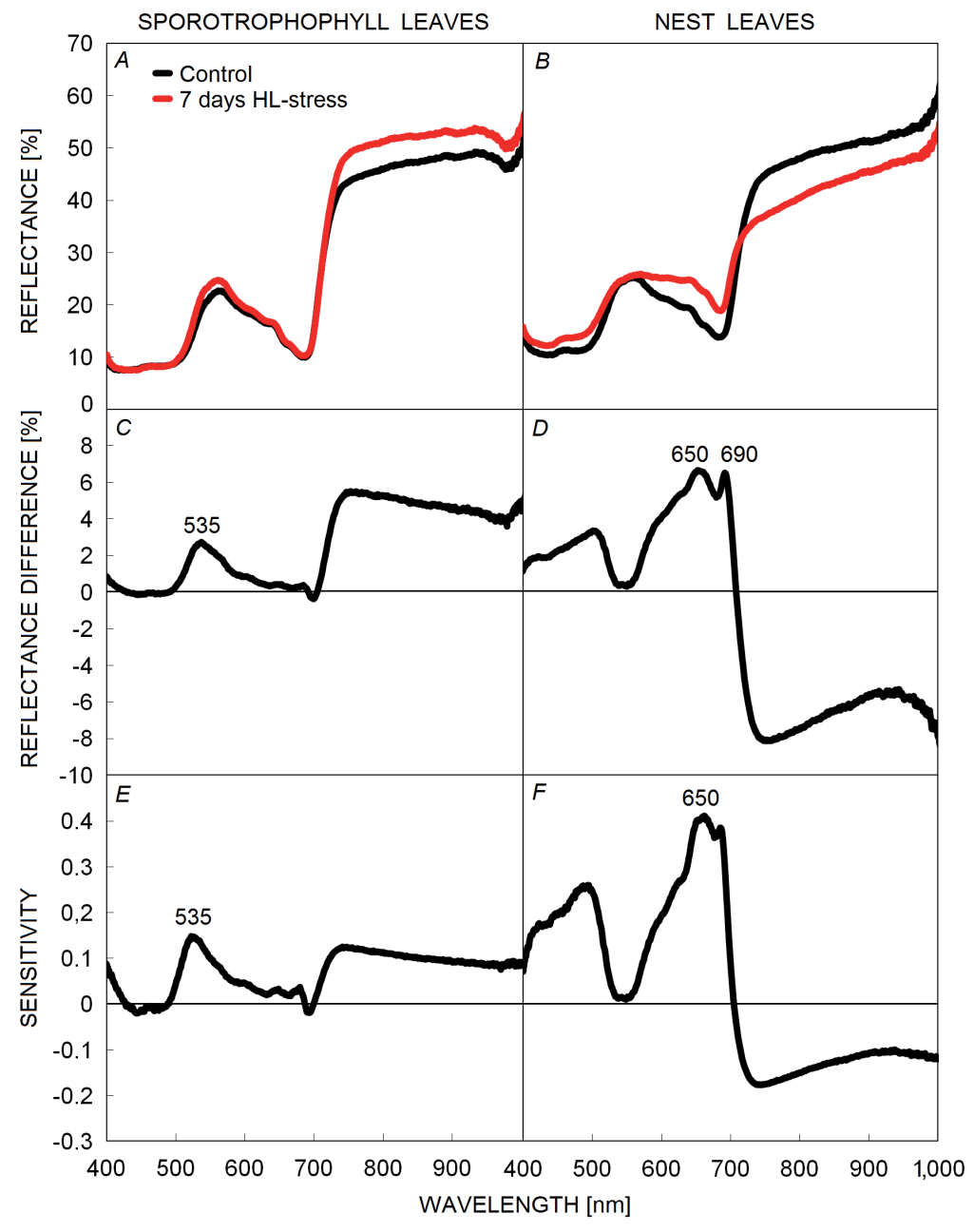

Fig. 5. Intensity of reflectance from sporotrophophylls $(A)$ and nest leaves $(B)$ of Platycerium bifurcatum after 7-d growth in high light (PPFD $=800 \mu \mathrm{mol} \mathrm{m} \mathrm{m}^{-2} \mathrm{~s}^{-1}$ ) and in control conditions

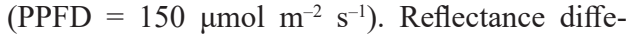
rence, produced by subtracting the mean values control plants from values of the stressed plants $(C, D)$. Sensitivity (no units), produced by dividing percentage reflectance difference by percentage reflectance values for control plants (E,F; methodology of Carter 1993), $n=7$. 
Table 1. Values of specific energy fluxes expressed per active PSII reaction center (RC) of the sporotrophophyll and nest leaves of Platycerium bifurcatum after 1 and 7 days growth in high light (PPFD $\left.=800 \mu \mathrm{m} \mathrm{m}^{-2} \mathrm{~s}^{-1}\right)$ and in control conditions $(\mathrm{PPFD}=150 \mu \mathrm{m}$ $\mathrm{m}^{-2} \mathrm{~s}^{-1}$ ). Values for the same leaf type marked with the same letters in the column do not differ significantly at $p \leq 0.05$ according to the Duncan's test, $n=7$.

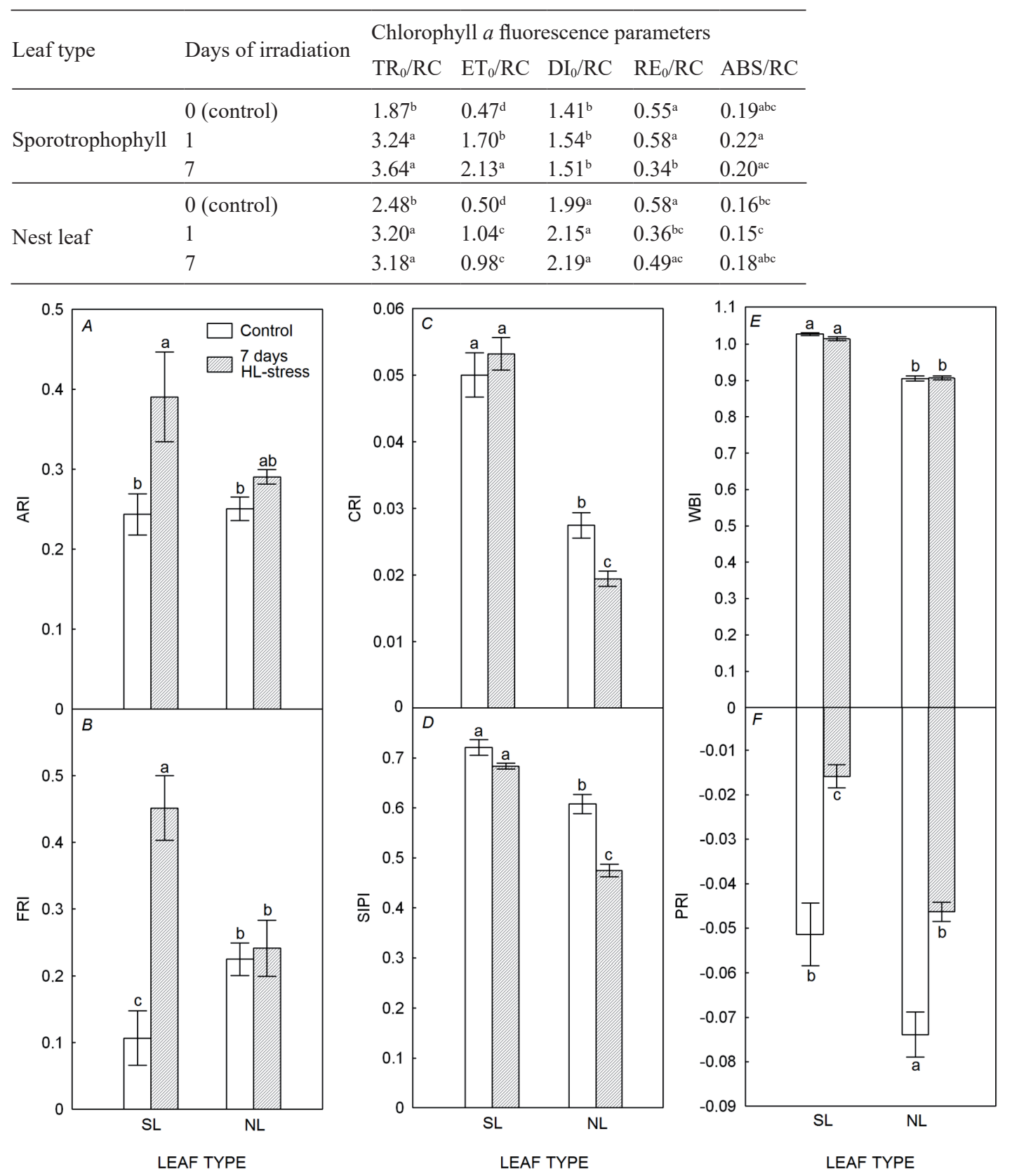

Fig. 6. Changes in the pigment composition and water content in sporotrophophylls (SL) and nest leaves (NL) of Platycerium bifurcatum after 7-d growth in high light (PPFD $=800 \mu \mathrm{mol} \mathrm{m}^{-2} \mathrm{~s}^{-1}$ ) and in control conditions (PPFD $=150 \mu \mathrm{mol} \mathrm{m}^{-2} \mathrm{~s}^{-1}$ ): $A-$ amount of anthocyanins (ARI), $B$ - amount of flavonoids (FRI), $C$ - amount of carotenoids (CRI), $D$ - ratio of carotenoids to chlorophyll content (SIPI), $E$ - amount of water (WBI), $F$ - photochemical reflectance index (PRI), $n=7$. Bars marked with the same letters do not differ significantly at $p \leq 0.05$ according to the Duncan's test, $n=7$.

highest in the green and infrared spectrum, with maximum values at the same wavelength as for RD (Fig. $5 E$ ). The minimum sensitivity occurred at $695 \mathrm{~nm}$. In turn, the nest leaves showed maximum sensitivity to light stress in the red spectrum $(650 \mathrm{~nm}-$ Fig. $5 F)$.
Changes in pigment composition and hydration of sporotrophophylls and nest leaves are shown in Fig. 6, using ARI, CRI, SIPI, FRI, and WBI parameters.

There was a large increase in the content of anthocyanin compounds (ARI) and flavonoids (FRI) after $7 \mathrm{~d}$ of HL 
stress in sporotrophophylls compared with the control (Fig. 6A,B). There were no changes in the content of Car pigments (CRI - Fig. $6 C$ ) and the Car/Chl ratio (SIPI - Fig. $6 D)$. In turn, the ARI value did not change, and CRI and SIPI decreased in the nest leaves under HL (Fig. $6 A, C, D$ ). The higher flavonoid contents (FRI) in control plants did not change after $7 \mathrm{~d}$ of plant growth under HL compared to sporotrophophylls. HL did not change tissue water content in both types of leaves (WBI - Fig. 6E). Differences in hydration between sporotrophophylls and nest leaves remained at the same level as in control plants.

Photosynthesis quantum yield associated with changes in the composition of xanthophyll pigments (PRI) was significantly lower in the nest leaves than that in sporotrophophylls both in control and under HL. However, HL caused a significant decrease in this coefficient in both types of leaves (Fig. $6 F$ ).

\section{Discussion}

Light stress in the epiphytic ferns: Light stress occurs when the amount of PAR absorbed by the photosynthetic pigments of the antenna complex is too large compared to the plant's capacity to convert it into the energy of chemical bonds. It results in decreased photosynthetic efficiency and photoinhibition, and in extreme cases, irreversible damage to PSII. However, even a short-term impairment of PSII can contribute to the loss of a significant part of the daily gain of assimilates (Raven 1989). Photoinhibition is often associated with the degradation of the $\mathrm{D}_{1}$ protein, responsible for $\mathrm{Q}_{\mathrm{A}}$ binding and deactivation of the repair mechanism, which regulates the balance between active and inactive RCs PSII (Flexas et al. 2001, Zhou et al. 2007). These inactive RCs, play an important role in PSII restitution by absorbing and dissipating excess energy after stress factor activation (Lee et al. 2001).

In epiphytes, light stress and associated photoinhibition rarely results in plant's death, however, when another stress factor is involved, especially drought, it often leads to inhibition of photosynthetic light phase processes (Lovelock et al. 1994). Then even moderate irradiation can contribute to serious disturbances in ontogenetic development (Durand and Goldstein 2001). Many epiphytes, including ferns, are less susceptible to HL stress than other plant species growing in the shade of tree crowns. Despite the relatively low values of the compensation point, many epiphytes have developed the ability to tolerate intense light (Lüttge et al. 1986). Among eight species of tropical epiphytic ferns subjected to several minutes of PAR action, with a photon flux intensity of $\leq 1,000 \mu \mathrm{mol} \mathrm{m} \mathrm{m}^{-2} \mathrm{~s}^{-1}$, none of the plants showed signs of photoinhibition (Hietz and Briones 2001). It is worth noting, however, that the evaluation included only the $\mathrm{F}_{\mathrm{V}} / \mathrm{F}_{\mathrm{M}}$ ratio. However, the long-term effect of HL (hours, days) more strongly differentiates epiphytic ferns in terms of excess light tolerance and resistance to photoinhibition. The degree of tolerance is often related to the distribution of plants within the canopy (Hietz and Briones 2001). Species growing on higher parts of trees and those growing on the edge of the forest usually show higher energy demand and higher tolerance for intensive radiation than those growing deep in the forest (Hietz and Briones 1998).

Despite different light intensity or diurnal temperature fluctuations, the relatively stable microclimate within the canopy of the tropical forest promotes the development of epiphytes and contributes to their species richness (Parker 1995). Light stress, however, can affect fern species distribution. Durand and Goldstein (2001) showed that some native species of ferns in Hawaii are characterized by lower tolerance for increased light intensity than the invasive species present there.

The presented work assumes that a rapid change in PPFD from 150 to $800 \mu \mathrm{mol} \mathrm{m} \mathrm{m}^{-2} \mathrm{~s}^{-1}$ must cause stress reactions in plants growing earlier under a 5-fold lower light intensity. However, it should be noted that in the natural environment plants are subject to fluctuations in the intensity of light, which results, for example, from the movement of leaves within the canopy and changing the position of the sun on the sky during the day. These light fluctuations are known as sunflecks (Chazdon 1988, Zhang et al. 2016). Thus, when analyzing the effect of light on plant metabolism under controlled conditions, it must be considered that growth chambers never fully reflect natural conditions. This is because in the environment occurrence of sunflecks may cause even local photoinhibition occurring only in the illuminated leaf fragment.

Analysis of OJIP curves: Abiotic stress factors such as strong light or drought usually result in disturbances in the electron transport chain (Foyer et al. 2012, Gururani et al. 2015). They are reflected in the shape of the Chl $a$ FL curve. Therefore, methods based on the OJIP test are often used in ecophysiological studies to assess the condition of the photosynthetic apparatus, especially PSII (Miszalski et al. 2016).

The analysis of OJIP curves shows that sporotrophophylls show a stronger response to HL than the nest leaves, especially after $7 \mathrm{~d}$ of growth under stressful conditions. Lack of definite differences in FL Chl $a$ curves between the first and seventh day in nest leaves indicates a fast but less sudden response of the photosynthetic apparatus and its lower susceptibility to excessive photon density or faster regeneration. It is interesting, because according to Rut et al. (2008), P. bifurcatum nest leaves utilize CAM metabolism. In turn, Adams and Osmond (1988) suggested that CAM-photosynthesis epiphytes, growing in the shade, exhibited high sensitivity to photoinhibition in HL.

Excitation energy losses during transfer to the PSII reaction center were visible in both types of leaves, although they intensified after a longer period of plant growth under HL only in sporotrophophylls. These disturbances were reported by the FL increase (compared with control) in the $\mathrm{O}-\mathrm{K}$ phase of the induction curve (Figs. $2 A, B ; 3 A$ ), high $\mathrm{F}_{0}(\mathrm{O}-$ point $)$ value and the appearance of the $\mathrm{L}$-band on the $\mathrm{O}-\mathrm{K}$ differential curve (characteristic for the effects of abiotic stress). The increase in Chl $a$ FL intensity on the first phase of the OJIP curve is usually associated with a decrease in energy transport efficiency between LHCII and the PSII reaction center (Tsimilli-Michael and 
Strasser 2013b). It also indicates a weaker connection of antenna complexes, which is related to the abnormal structure of thylakoids. An increase in L band intensity in sporotrophophylls after $7 \mathrm{~d}$ under HL (Fig. 2C) is probably associated with progressive degradation of LHCII proteins. It involves FtsH6 protease, constitutionally present in small amounts in the thylakoids and participating in plant acclimation to the conditions of strong radiation (Żelisko et al. 2005). In turn, the occurrence of the maximum $\mathrm{L}$ band shifted in time, observed after $7 \mathrm{~d}$, demonstrated slower energy transfer from the antennas to RC (Kalaji et al. 2018). This shift in the nest leaves was observed after just one day under HL and confirmed a faster response to stressful conditions than that in sporotrophophylls (Fig. 3C).

The analysis of the $\mathrm{O}-\mathrm{J}$ phase of $\mathrm{Chl} a \mathrm{FL}$ induction curves (Figs. $2 A, 3 A)$ as well as differential curves $\left(\Delta \mathrm{Vt}_{\mathrm{O}-\mathrm{J}}\right.$ - Figs. $2 D, 3 D$ ) allow to describe the state of the PSII donor side under stress conditions and illustrate the size and absorption capacity of LHCII (Tsimilli-Michael and Strasser 2013a). The biggest differences between the $1^{\text {st }}$ and $7^{\text {th }}$ day of HL stress were visible in nest leaves in the course of the $\mathrm{O}-\mathrm{J}$ phase, which is strongly light-dependent (Dąbrowski et al. 2016). Differential curves for this phase visualized the presence of a distinct $\mathrm{K}$ band (Fig. 3D). High positive $\mathrm{K}$ band values (observed already after $1 \mathrm{~d}$ of plant growth in HL) prove the rapid oxidation-reduction imbalance between the OEC and the PSII reaction center. They are caused by OEC damage, which is extremely sensitive to changes in environmental conditions (Strasser 1997, Kalaji et al. 2018). The lack of the $\mathrm{K}$ band in sporotrophophylls, after $1 \mathrm{~d}$ under HL and only a low intensity $\mathrm{K}$ band after $7 \mathrm{~d}$ (Fig. 2D), suggests induction of a mechanism that would compensate for the abnormal functioning of OEC. However, these mechanisms do not sufficiently improve PSII function. This is evidenced by large deviations from the control values in other phases of the OJIP curve (Fig. 2A), as well as decreased values of Chl $a$ FL parameters, such as $\mathrm{F}_{\mathrm{V}} / \mathrm{F}_{0}, \mathrm{~F}_{\mathrm{V}} / \mathrm{F}_{\mathrm{M}}, \mathrm{PI}, \mathrm{F}_{\mathrm{K}} / \mathrm{F}_{\mathrm{J}}$, especially after $7 \mathrm{~d}$ of stress (Fig. $4 A$ ). It seems, however, that changes in the functioning of OEC caused by stress are too complicated to be explained only by the OJIP test.

Disturbances of electron transport at the plastoquinone reduction stage, observed in sporotrophophylls (Fig. 2E), increased during the longer exposure to HL, as evidenced by clear bands in the J-I phase. On the other hand, negative $G$ band values in the I-P phase illustrated the course of reduction of the PSI acceptor side. More negative $\mathrm{G}$ band values, visible after $7 \mathrm{~d}$, corresponded to the growing number of NADPH molecules per active RC under abiotic stress (Tsimilli-Michael and Strasser 2013a). Similar dependencies were also observed in the case of other abiotic stresses, e.g., micro- and macro-nutrient deficiencies or salt stress, as well as during the aging process (Bąba et al. 2016, Dąbrowski et al. 2016, Kalaji et al. 2018). In contrast to sporotrophophylls, curves obtained for the nest leaves at J-I and I-P phases (Fig. 3E-F) did not indicate disturbances in energy flux between the plastoquinone pool and PSI and proved lower susceptibility of the photosynthetic apparatus to photoinhibition. In conclusion, the stage of the photosynthetic light phase, at which the main HL effects occur, depends on a leaf type. Disturbances in the initial reactions of the light phase were characteristic for the nest leaves. In sporotrophophylls, subsequent reactions associated with the reduction of $\mathrm{PQ}$ and PSI acceptors were primarily impaired. However, negative changes in LHCII were visible only after a longer period of HL exposure.

Chl $\boldsymbol{a}$ FL parameters: The effects of photoinhibition and disintegration of the photosynthetic apparatus are reflected in changes in Chl $a$ FL parameters (Fig. 4). The decrease in the maximum quantum yield of PSII $\left(\mathrm{F}_{\mathrm{V}} / \mathrm{F}_{\mathrm{M}}\right)$ by $37 \%$ in sporotrophophylls and by $13 \%$ in nest leaves, compared with control, occurred after $1 \mathrm{~d}$ of plant growth in HL. It indicated, especially in sporotrophophylls, strong photoinhibition, which already occurred at PPFD of 800 $\mu \mathrm{mol} \mathrm{m} \mathrm{m}^{-2} \mathrm{~s}^{-1}$, which is almost half lower than this applied by Sanusi et al. (2011) in their study on P. bifurcatum. A decrease in $F_{V} / F_{M}$ after a 2-d HL exposure was also demonstrated for eight other species of epiphytic ferns growing in tropical forests of Mexico (Hietz and Briones 2001). This decrease for Asplenium cuspidatum, which grows naturally in the shade inside the canopy, was 37\%, whereas the average $\mathrm{F}_{\mathrm{V}} / \mathrm{F}_{\mathrm{M}}$ value decreased by $10 \%$ in Elaphoglossum petiolatum, growing in sites with better sunlight exposure (in comparison to control). A strong light intensity disturbed the growth and development, and limited functioning of photoprotective mechanisms in the leaf also in epiphytic orchid species, which was associated with a decrease in the $\mathrm{F}_{\mathrm{V}} / \mathrm{F}_{\mathrm{M}}$ value (Stancato et al. 2002).

Until now, the ecophysiological studies on light stress in epiphytes were mainly based on the $F_{V} / F_{M}$ ratio analysis, but other parameters of PSII efficiency were not determined (Hietz and Briones 2001, Stancato et al. 2002). However, as our research shows, the $F_{V} / F_{0}$ and PI coefficients are more sensitive indicators of environmental stress, better describing different response during the light phase. The decrease in the $\mathrm{F}_{\mathrm{V}} / \mathrm{F}_{0}$ value indicates damage to the thylakoid structure in chloroplasts (Pereirea et al. 2000). Changes in PI values determine the overall vitality of the plant and its viability, combining information on the number of active RCs on $\mathrm{Chl}$ and initial reactions of the light phase with data on electron flux through RC (Kalaji et al. 2014). A decrease in sporotrophophyll vitality, to $13 \%$ of the control value after $1 \mathrm{~d}$ of HL stress, indicated a drastic reduction in the efficiency of energy conversion in PSII (Bąba et al. 2016). However, in the nest leaves, despite the initial decrease in PI, a slight improvement in RC energy efficiency was observed after $7 \mathrm{~d}$ (Fig. 4). This can be explained by an entirely different ontogenesis compared to sporotrophophylls, i.e., short period of leaf growth and the following fast aging process, combined with the loss of assimilation properties (Oliwa et al. 2017). The study of Lovelock et al. (1994) demonstrated that a short leaf life span in some tropical fern species was associated with their ability to regenerate faster after photoinhibition. It is possible that this was due to the faster rate of photosynthesis (Reich et al. 1997).

The OEC in both types of leaves was damaged under 
HL (Fig. 4, $F_{K} / F_{J}$ value - Srivastava and Strasser 1995). In addition, an increase of $\mathrm{M}_{0}$ value was observed. This parameter is related to the rate of closure of reaction centers (Bąba et al. 2016). In sporotrophophylls, this parameter increased between $1^{\text {st }}$ and $7^{\text {th }}$ day under HL, which was not observed in the nest leaves. This confirms the different reaction to HL stress in the photosynthetic apparatus of sporotrophophylls. Changes in the values of $\mathrm{TR}_{0} / \mathrm{RC}, \mathrm{ET}_{0} / \mathrm{RC}$ (Table 1 ) in both types of leaves indicate an increase in the efficiency of trapped and transport of electrons by RC. HL does not affect the amount of energy dissipated in the form of heat $\left(\mathrm{DI}_{0} / \mathrm{RC}\right)$. However, in the nest leaves, $\mathrm{DI}_{0} / \mathrm{RC}$ values were significantly higher than that in sporotrophophylls.

Reflectance analysis: Plant pigments strongly absorb visible radiation in the $400-700 \mathrm{~nm}$ range. The decrease in pigment contents in the tissue results in a reduction of the absorption capacity, and thus an increase in the intensity of reflectance. This corresponds to the degree of light energy utilization, which can be treated as an indicator of assimilate-production efficiency (Araus et al. 2001). Reflectance analysis, as opposed to classical biochemical methods, allows for fast and nondestructive assessment of leaf pigment composition (Gamon and Surfus 1999, Solovchenko 2010). In turn, measurements performed on individual leaves allow to avoid interpretation problems resulting from the complex spatial structure of the plant (Linke et al. 2008).

The increase in reflectance intensity in sporotrophophylls after $7 \mathrm{~d}$ of HL is typical for stressful conditions. It is probably associated with changes in the leaf color profile (Solovchenko 2010). An increase in PAR reflectance is usually associated with a decrease in the Chl content and is a general detector of plant stress (Cibula and Miller 1996, Carter and Knapp 2001). Differences in reflectance between sporotrophophylls and nest leaves in the farred and near-infrared range may result from different morphological and anatomical structure of these leaves.

The analysis of reflectance difference (RD) and determination of stress-sensitive wavelengths are also helpful in the assessment of changes caused by stress in plants (Cibula and Carter 1992). The 535-nm band, visible in sporotrophophylls (Fig. 5C,E), and $690 \mathrm{~nm}$ in nest leaves (Fig. $5 D, F$ ), correspond to the bands observed in various plant species subjected to stress, such as drought, deficiency of mineral elements, fungal infections, and other (Carter 1993, Moran et al. 2000). The reflectance coefficient showed usually the highest sensitivity to stress in the 535-540 $\mathrm{nm}$ and 685-700 $\mathrm{nm}$ ranges (Carter 1993). RD spectral bands of 535 and $650 \mathrm{~nm}$ can therefore be characteristic of the HL-stress response in Platycerium, and possibly in other ferns. However, acclimation to intense light by growing plants at an elevated $\mathrm{R} / \mathrm{FR}$ ratio in the light spectrum can change this picture (Oliwa and Skoczowski - unpublished data). However, the maximum $\mathrm{RD}$ and sensitivity values fall within the range of 400 $850 \mathrm{~nm}$ in all cases.

Changes in pigment composition of sporotrophophylls influenced by HL were observed to a much greater extent than that in the nest leaves. The pronounced increase in the content of anthocyanins and flavonoids demonstrated the defense response of sporotrophophylls (Fig. 6A,B). Accumulation of photoprotectants, including anthocyanins and flavonoids, is very common in plants exposed to intense radiation in the PAR and UV range and is intended to protect thylakoid membranes (Chalker-Scott 1999, Gitelson et al. 2003, 2009, Steele et al. 2009). Excess PAR implies, in addition to disturbances in electron transport, the generation of singlet oxygen in the $\mathrm{P}_{680}$ triplet, especially dangerous for chloroplast membranes (Baroli and Melis 1998, Burritt and MacKenzie 2003). Rapid production of flavonoid compounds, as a response to HL, supports the inhibition of reactive oxygen species production and stabilizes chloroplast membranes (Agati et al. 2012). In turn, the presence of Car pigments of the xanthophyll cycle in thylakoids separates LHCII that receives excess energy from the PSII reaction center. This enables the protection of the most sensitive part of the photosynthetic apparatus (Walters and Horton 1993, Gilmore and Yamamoto 1993). There was no increase in the amount of anthocyanins and flavonoids in cover leaves. In addition, a slight decrease in Car contents and a quantitative ratio of Car to Chl (SIPI), which usually increases during HL exposure, was observed (Young and Britton 1990). This suggests that the main defense mechanisms were aimed to protect assimilation organs (i.e., sporotrophophylls).

The decrease in the amount of water in the tissue results in a lower value of the WBI parameter (Peñuelas et al. 1993). WBI values (Fig. 6E) were typical for assimilating tissues in both leaf types (0.8-1.2 i.u. - Peñuelas et al. 1997). Lack of significant changes in the water content under HL conditions compared to control may indicate the absence of disturbances in leaf stomatal conductance. On the other hand, lower WBI values in nest leaves were results of their different morphological and anatomical structure (Oliwa et al. 2017).

Reduction of the photochemical reflectance index (PRI), which occurred in both types of leaves, describes rapid changes in the pigment profile of the xanthophyll cycle under HL and is associated with deepoxidation of xanthophyll pigments (Filella et al. 1996, Sims and Gamon 2002, Peñuelas et al. 2011). In addition, it illustrates the intensity of nonphotochemical dissipation (Naumann et al. 2008). Lower PRI values in the nest leaves than that in sporotrophophylls in both control and HL conditions indicated better light use by the nest leaves (Gamon et al. 1997 - Fig. $6 F$ ).

In summary, $P$. bifurcatum sporotrophophylls showed a stronger response to HL stress than the nest leaves. The disturbances of electron transport occurring at various stages of the light phase led to a decrease in the vitality of the photosynthetic apparatus. However, it seems that sporotrophophylls use photoprotective mechanisms associated with the accumulation of flavonoid compounds and anthocyanins more efficiently than the nest leaves. Differences in the response to HL between the two types of leaves may result from the different role they play in the examinated fern. 


\section{References}

Adams W.W. III, Osmond C.B.: Internal $\mathrm{CO}_{2}$ supply during photosynthesis of sun and shade grown CAM plants in relation to photoinhibition. - Plant Physiol. 86: 117-123, 1988.

Adibah R-M.S., Ainuddin A.N.: Epiphytic plants responses to light and water stress. - Asian J. Plant Sci. 10: 97-107, 2011.

Agati G., Azzarello E., Pollastri S., Tattini M.: Flavonoids as antioxidants in plants: location and functional significance. Plant Sci. 196: 67-76, 2012.

Araus J.L., Slafer G. A., Royo C., Serret M.D.: Breeding for yield potential and stress adaptation in cereals. - Crit. Rev. Plant Sci. 27: 377-412, 2001.

Aspiras R.A.: Sporophyte and gametophyte development of Platycerium coronarium (Koenig) Desv. and P. grande (Fee) C. Presl. (Polypodiaceae) through in vitro propagation. Saudi J. Biol. Sci. 17: 13-22, 2010.

Baroli I., Melis A.: Photoinhibitory damage is modulated by the rate of photosynthesis and by the photosystem II lightharvesting chlorophyll antenna size. - Planta 205: 288-296, 1998.

Barthlott W., Schmit-Neuerburg V., Nieder J., Engwald S.: Diversity and abundance of vascular epiphytes: A comparison of secondary vegetation and primary montane rain forest in the Venezuelan Andes. - Plant Ecol. 152: 145-156, 2001.

Bąba W., Kalaji H.M., Kompała-Bąba A., Goltsev V.: Acclimatization of photosynthetic apparatus of tor grass (Brachypodium pinnatum) during expansion. - PLoS ONE 11: e0156201, 2016.

Bertamini M., Muthuchelian K., Nedunchezhian N.: Photoinhibition of photosynthesis in sun and shade grown leaves of grapevine (Vitis vinifera L.). - Photosynthetica 42: 7-14, 2004.

Brestic M., Zivcak M., Kunderlikova K. et al.: Low PSI content limits the photoprotection of PSI and PSII in early growth stages of chlorophyll $b$-deficient wheat mutant lines. Photosynth. Res. 125: 151-166, 2015.

Burritt D.J., MacKenzie S.: Antioxidant metabolism during acclimation of Begonia $\times$ erythrophylla to high light levels. Ann. Bot.-London 91: 783-794, 2003.

Carter G., Knapp A.: Leaf optical properties in higher plants: linking spectral characteristics to stress and chlorophyll concentration. - Am. J. Bot. 88: 677-684, 2001.

Carter G.A.: Responses of leaf spectral reflectance to plant stress. - Am. J. Bot. 80: 239-243, 1993.

Chalker-Scott L.: Environmental significance of anthocyanins in plant stress responses. - Photochem. Photobiol. 70: 1-9, 1999.

Chazdon R.L.: Sunflecks and their importance to forest understorey plants. - Adv. Ecol. Res. 18: 1-63, 1988.

Chernev P., Goltsev V., Strasser R.J.: A highly restricted model approach quantifying structural and functional parameters of Photosystem II probed by the chlorophyll $a$ fluorescence rise. - Ecol. Engin. Ecol. Protect. 6: 19-29, 2006.

Cibula W. G., Carter G. A.: Identification of a far-red reflectance response to ectomycorrhizae in slash pine. - Int. J. Remote Sens. 13: 925-932, 1992.

Cibula W.G., Miller R.L.: Narrow-band reflectance imagery compared with thermal imagery for early detection of plant stress. - J. Plant Physiol. 148: 516-523, 1996.

Cooney L.J., Logan B.A., Walsh M.J.L. et al.: Photoprotection from anthocyanins and thermal energy dissipation in senescing red and green Sambucus canadensis peduncles. Environ. Exp. Bot. 148: 27-34, 2018.

Dąbrowski P., Baczewska A.H., Pawluśkiewicz B. et al.: Prompt chlorophyll $a$ fluorescence as a rapid tool for diagnostic changes in PSII structure inhibited by salt stress in Perennial ryegrass. - J. Photochem. Photobiol. B. 157: 22-31, 2016.

Demmig-Adams B., Adams W.W. III: An integrative approach to photoinhibition and photoprotection of photosynthesis. Environ. Exp. Bot. 154: 1-3, 2018.

Demmig-Adams B., Stewart J.J., Adams W.W. III: Environmental regulation of maximal photosynthetic capacity. - Cur. Opin. Plant Biol. 37: 34-41, 2017.

Durand L.Z., Goldstein G.: Photosynthesis, photoinhibition, and nitrogen use efficiency in native and invasive tree ferns in Hawaii. - Oecologia 126: 345-354, 2001.

Eickmeier W.G., Casper C., Osmond C.B.: Chlorophyll fluorescence in the resurrection plant Selaginella lepidophylla (Hook \& Grev) Spring during high-light and desiccation stress, and evidence for zeaxanthin-associated photoprotection. Planta 189: 30-38, 1993.

Filella I., Amaro T., Araus J.L, Penuelas J.: Relationship between photosynthetic radiation-use efficiency of barley canopies and the photochemical reflectance index (PRI). - Physiol. Plantarum 96: 211-216, 1996.

Flexas J., Hendrickson L., Chow W.S.: Photoinactivation of photosystem II in high light-acclimated grapevines. - Aust. J. Plant. Physiol. 28: 755-764, 2001.

Force L., Critchley C., van Rensen J.J.S.: New fluorescence parameters for monitoring photosynthesis in plants. - Photosynth. Res. 78: 17-33, 2003.

Forget, S.E., Parker, E.M., Hughes, N.M.: Effects of leaf prostration on microclimate and ecophysiology of the evergreen fern Polystichum acrostichoides. - Environ. Exp. Bot. 154: 80-88, 2018.

Foyer C.H.: Reactive oxygen species, oxidative signaling and the regulation of photosynthesis. - Environ. Exp. Bot. 154: 134142, 2018.

Foyer, C.H., Neukermans, J., Queval, G., Noctor, G., Harbinson, J.: Photosynthetic control of electron transport and the regulation of gene expression. - J. Exp. Bot. 63: 1637-1661, 2012.

Gamon A., Serrano L., Surfus S.: The photochemical reflectance index: an optical indicator of photosynthetic radiation use efficiency across species, functional types, and nutrient levels. - Oecologia 112: 492-501, 1997.

Gamon J.A., Peñuelas J., Field C.B.: A narrow-waveband spectral index that tracks diurnal changes in photosynthetic efficiency. - Remote Sens. Environ. 41: 35-44, 1992.

Gamon J.A., Surfus J.S.: Assessing leaf pigment content and activity with a reflectometer. - New Phytol. 143: 105-117, 1999.

Gilmore A. M., Yamamoto H. Y.: Linear models relating xanthohylls and lumen acidity to non-photochemical fluorescence quenching. Evidence that antheraxanthin explains zeaxanthinindependent quenching. - Photosynth. Res. 35: 67-78, 1993.

Gitelson A., Chivkunova O., Merzlyak M.: Nondestructive estimation of anthocyanins and chlorophylls in anthocyanic leaves. - Am. J. Bot. 96: 1861-1868, 2009.

Gitelson A., Gritz Y., Merzlyak M.: Non-destructive chlorophyll assessment in higher plant leaves: algorithms and accuracy. J. Plant. Physio. 160: 271-282, 2003.

Gitelson A.A., Merzylak M.N., Chivkunova O.B.: Optical properties and nondestructive estimation of anthocyanin content in plant leaves. - Photochem. Photobiol. 71: 38-45, 2001.

Gitelson A.A., Zur Y., Chivkunova O.B., Merzylak M.N.: Assessing carotenoid content in plant leaves with reflectance spectroscopy. - Photochem. Photobiol. 75: 272-281, 2002.

Gould K.S., Jay-Allemand C., Logan B.A. et al.: When are foliar anthocyanins useful to plants? Re-evaluation of the photoprotection hypothesis using Arabidopsis thaliana 
mutants that differ in anthocyanin accumulation. - Environ. Exp. Bot. 154: 11-22, 2018.

Gururani M.A., Venkatesh J., Tran L.-S.P.: Regulation of photosynthesis during abiotic stress-induced photoinhibition. - Mol. Plant 8: 1304-1320, 2015.

Hietz P., Briones O.: Correlation between water relations and within-canopy distribution of epiphytic ferns in a Mexican cloud forest. - Oecologia 114: 305-316, 1998.

Hietz P., Briones O.: Photosynthesis, chlorophyll fluorescence and within-canopy distribution of epiphytic ferns in a mexican cloud forest. - Plant. Biol. 3: 279-287, 2001.

Kalaji H.M., Bąba W., Gediga K.: Chlorophyll fluorescence as a tool for nutrient status identification in rapeseed plants. - Photosynth. Res. 136: 329-343, 2018.

Kalaji H.M., Carpentier R., Allakhverdiev S.I., Bosa K.: Fluorescence parameters as early indicators of light stress in barley. - J. Photoch. Photobio. B 112: 1-6, 2012.

Kalaji M.H., Guo P.: Chlorophyll fluorescence: A useful tool in barley plant breeding programs. - In: Sanchez A., Gutierrez S. J. (ed.): Photochemistry Research Progress. Pp. 439-463. Nova Publishers, New York, 2008.

Kalaji M.H., Jajoo A., Oukarroum A. et al.: The use of chlorophyll fluorescence kinetics analysis to study the performance of photosynthetic machinery in plants. - Emerg. Technol. Manag. Crop Stress Tol. 2: 347-384, 2014.

Lee H-Y., Chow W.S., Hong Y-N.: Photoinactivation of photosystem II complexes and photoprotection by nonfunctional neighbours in leaves of Capsicum annuum L. Planta 212: 332-342, 2001.

Li Z., Wakao S., Fischer B.B., Niyogi K.K.: Sensing and responding to excess light. - Annu. Rev. Plant Biol. 60: 239260, 2009.

Liao Y.K., Wu Y.H.: In vitro propagation of Platycerium bifurcatum (Cav.) C. Chr. via green globular body initiation. Bot. Stud. 52: 455-463, 2011.

Lichtenthaler H.K., Burkart S.: Photosynthesis and high light stress. - Bulg. J. Plant Physiol. 25: 3-16, 1999.

Linke R., Schneider W., Weihs P.: Occurrence of repeated drought events: can repetitive stress situations and recovery from drought be traced with leaf reflectance. - Period. Biol. 110: 219-229, 2008.

Logan B.A., Demmig-Adams B., Adams W.W., Bilger W.: Context, quantification, and measurement guide for nonphotochemical quenching of chlorophyll fluorescence. - In: Demmig-Adams, B., Garab G., Adams W., Govindjee (ed.): Non-Photochemical Quenching and Energy Dissipation in Plants, Algae and Cyanobacteria. Pp. 187-201. Springer, Dordrecht 2014.

Lovelock C.E., Jebb M., Osmond C.B.: Photoinhibition and recovery in tropical plant species: response to disturbance. Oecologia 97: 297-307, 1994.

Lüttge U., Ball E., Kluge M., Ong B. L.: Photosynthetic light requirements of various tropical vascular epiphytes. - Physiol. Veg. 24: 315-331, 1986.

MalnoëA.: Photoinhibition or photoprotection of photosynthesis? Update on new sustained quenching component, qH. Environ. Exp. Bot. 154: 123-133, 2018.

Mehta P., Allakhverdiev S.I., Jajoo A.: Characterization of photosystem II heterogeneity in response to high salt stress in wheat leaves (Triticum aestivum). - Photosynth. Res. 105: 249-255, 2010.

Merzlyak M.N., Solovchenko A.E., Smagin A.I., Gitelson A.A.: Apple flavonols during fruit adaptation to solar radiation: spectral features and technique for non-destructive assessment. - J. Plant. Physiol. 162: 151-160, 2005.

Miszalski Z., Skoczowski A., Silina E. et al.: Photosynthetic activity of vascular bundles in Plantago media leaves. J. Plant. Physiol. 204: 36-43, 2016.

Moran J.A., Mitchell A.K., Goodmanson G., Stockburger K.A.: Differentiation among effects of nitrogen fertilization treatments on conifer seedlings by foliar reflectance: a comparison of methods. - Tree Physiol. 20: 1113-1120, 2000.

Naumann J.C., Young D.R., Anderson J.E.: Leaf chlorophyll fluorescence, reflectance and physiological response to freshwater and saltwater flooding in the evergreen shrub, Myrica cerifera. - Environ. Exp. Bot. 63: 402-404, 2008.

Oukarroum A., El Madidi S., Schansker G., Strasser R.J.: Probing the responses of barley cultivars (Hordeum vulgare L.) by chlorophyll a fluorescence OLKJIP under drought stress and re-watering. - Environ. Exp. Bot. 60: 438-446, 2007.

Oliwa J., Kornas A., Skoczowski A.: A low ratio of red/far-red in the light spectrum accelerates senescence in nest leaves of Platycerium bifurcatum. - Acta Biol. Cracov. Ser. Bot. 59: 6780, 2017.

Parker G.G.: Structure and microclimate of forest canopies. - In: Lowman M., Nadkarni N.M. (ed.): Forest Canopies. Pp. 73106. Academic Press, San Diego 1995.

Peñuelas J., Filella I., Baret F.: Semiempirical indices to assess carotenoids/ chlorophyll $a$ ratio from leaf spectra reflectance. - Photosynthetica 31: 221-230, 1995.

Peñuelas J., Filella I., Biel C. et al.: The reflectance at the 950$970 \mathrm{~nm}$ region as an indicator of plant water status. - Int. J. Remote Sens. 14: 1887-1905, 1993.

Peñuelas J., Garbulsky M.F., Filella I.: Photochemical reflectance index (PRI) and remote sensing of plant $\mathrm{CO}_{2}$ uptake. - New Phytol. 191: 596-598, 2011.

Peñuelas J., Piñol J., Ogaya R., Filella I.: Estimation of plant water concentration by the reflectance water index WI (R900/ R970). - Int. J. Remote Sens. 18: 2869-2875, 1997.

Pereira W.E., de Siqueira D.L., Martínez C.A., Puiatti M.: Gas exchange and chlorophyll fluorescence in four citrus rootstocks under aluminium stress. - J. Plant Physiol. 157: 513-520, 2000.

Raven J.A.: Fight or flight: the economics of repair and avoidance of photoinhibition of photosynthesis. - Funct. Ecol. 3: 5-19, 1989.

Reich P.B., Walters M.B., Ellsworth D.S.: From tropics to tundra: global convergence in plant functioning. - Ecology 94: 13730-13734, 1997.

Rut G., Krupa J., Rzepka A.: The influence of simulated osmotic drought on functioning of the photosynthetic appratus in gametophytes of the epiphytic fern Platycerium bifurcatum. - Pol. J. Nat. Sci. S1: 144-145, 2003.

Rut G., Krupa J., Miszalski Z. et al.: Crassulacean acid metabolism in the epiphytic fern Platycerium bifurcatum. Photosynthetica 46: 156-160, 2008.

Sanusi R-A.M., Nuruddin A.A., Hamid H.A.: Leaf chlorophyll fluorescence and gas exchange response to different light levels in Platycerium bifurcatum. - Am. J. Agr. Biol. Sci. 6: 214-220, 2011.

Sims D.A., Gamon J.A.: Relationships between leaf pigment content and spectral reflectance across a wide range of species, leaf structures and developmental stages. - Remote Sens. Environ. 81: 337-354, 2002.

Solovchenko A.: Quantification of screening pigments and their efficiency in situ. - In: Solovchenko A. (ed.): Photoprotection in Plants, Springer Series in Biophysics 14. Pp. 119-141. Springer-Verlag Berlin, Heidelberg 2010.

Srivastava A., Strasser R.J.: How do land plants respond to stress temperature and stress light? - Arch. Sci. Geneve 48: 135$146,1995$.

Stancato G.C., Mazzafera P., Buckeridge M.S.: Effects of light 
stress on the growth of the epiphytic orchid Cattleya forbesii Lindl. × Laelia tenebrosa Rolfe. - Rev. Bras. Bot. 25: 229235, 2002.

Steele M., Gitelson A., Rundquist D., Merzlyak M.: Nondestructive estimation of anthocyanin content in grapevine leaves. - Am. J. Enol. Viticult. 60: 87, 2009.

Stirbet A., Govindjee: On the relation between the Kautsky effect (chlorophyll $a$ fluorescence induction) and Photosystem II: Basics and applications of the OJIP fluorescence transient. J. Photoch. Photobio. B 104: 236-257, 2011.

Strasser B.: Donor side capacity of photosystem II probed by chlorophyll a fluorescence transients. - Photosynth. Res. 52: 147-155, 1997.

Strasser R.J., Srivastava A., Tsimilli-Michael M.: The fluorescence transient as a tool to characterize and screen photosynthetic samples. - In: Yunus M., Pathre U., Mohanty P. (ed.): Probing Photosynthesis: Mechanism Regulation and Adaptation. Pp. 443-480. Taylor and Francis, London 2000.

Strasser R.J, Tsimilli-Michael M., Srivastava A.: Analysis of the chlorophyll $a$ fluorescence transient. - In: Papageorgiou G.C., Govindjee (ed.): Chlorophyll $a$ Fluorescence. Pp. 321-362. Springer, Dordrecht 2004.

Tausz M., Hietz P., Briones O.: The significance of carotenoids and tocopherols in photoprotection of seven epiphytic fern species of a Mexican cloud forest. - Aust. J. Plant Physiol. 28: 775-783, 2001.

Tsimilli-Michael M., Strasser R.J.: Biophysical phenomics: evaluation of the impact of mycorrhization with Piriformospora indica. - In: Varma A., Kost G., Oelmüller R. (ed.): Piriformospora indica. Pp. 173-190. Springer, Berlin 2013a.

Tsimilli-Michael M., Strasser R.J.: The energy flux theory 35 years later: formulations and applications. - Photosynth. Res. 117: 289-320, 2013b.

Vanhee C., Zapotoczny G., Masquelier D. et al.: The Arabidopsis multistress regulator TSPO is a heme binding membrane protein and a potential scavenger of porphyrins via an autophagy-dependent degradation mechanism. - Plant Cell 23: 785-805, 2011

Walters R.G., Horton P.: Theoretical assessment of alternative mechanisms for nonphotochemical quenching of PSII fluorescence in barley leaves. - Photosynth. Res. 36: 119-139, 1993.

Weng J.H., Lai M.F.: Estimating heat tolerance among plant species by two chlorophyll fluorescence parameters. Photosynthetica 43: 439-444, 2005.

Young A., Britton G.: Carotenoids and stress. - In: Ruth G. A., Cumming J. R. (ed.): Stress Responses in Plants: Adaptation and Acclimation Mechanisms. Pp. 87-112. Wiley-Liss, New York 1990.

Yusuf M.A., Kumar D., Rajwanshi R. et al.: Overexpression of g-tocopherol methyl transferase gene in transgenic Brassica juncea plants alleviates abiotic stress: physiological and chlorophyll a fluorescence measurements. - Biochim. Biophys. Acta 1797: 1428-1438, 2010.

Zhang C.G., Liu X., Fan Y.L.: Sunfleck limits the small-scale distribution of endangered Kingdonia uniflora in the natural habitat of subalpine forest proved by its photosynthesis. Acta Physiol. Plant 38: 100, 2016.

Zhou Y, Lam H.M, Zhang J.: Inhibition of photosynthesis and energy dissipation induced by water and high light stresses in rice. - J. Exp. Bot. 58: 1207-1217, 2007.

Zotz G., Hietz P.: The physiological ecology of vascular epiphytes: current knowledge, open questions. - J. Exp. Bot. 52: 2067-2078, 2001.

Żelisko A., Garcia-Lorenzo M., Jackowski G. et al.: AtFtsH6 is involved in the degradation of the light-harvesting complex II during high-light acclimation and senescence. - P. Natl. Acad. Sci. USA 102: 13699-13704, 2005.

(C) The authors. This is an open access article distributed under the terms of the Creative Commons BY-NC-ND Licence. 